Jecker's book leads the reader through a varied thicket of perspectives on aging and the old. One comes away not only with a clear sense of the issues at stake in health care debates but also with a strong incentive for reflecting on our general assumptions about senior citizens, assumptions that often exert an insidious influence on social policy.

Among the book's many strengths is its insistence, filtered through several essays and authors, on confronting the philosophical complexity beneath many of medicine's most disconcerting practical problems. In deference to this, the editor has buttressed the more applied essays at the centre of the collection with distinctly reflective pieces at the volume's beginning and end. This thoughtful arrangement reveals the connectedness of concepts about aging, health and the meaning of life in an effective and compelling manner.

Section one, 'The aging individual' offers insight into the place of an older person's viewpoint on the value of a life seen as a whole. The essays reflect the calm distance of analytic philosophy and the sweeping vision of social survey; they weave classical myth and modern living, and explore the phenomenology of the aging body. Sally Gadow's 'Recalling the body in aging' strikes a provocative chord in its juxtaposition of the persistent inner self with social expectations, as they act upon the outer self of a changing body.

In 'Aging and filial responsibility', the book's second section, several diverse essays stress the increasingly strained relationship that often obtains between the elderly relative and the family caregiver in home-based care situations. Among the themes considered are shifting autonomy for some older persons, duties owed to one's parents and duties owed as well to the overwhelmingly female home-caregivers who almost always remain unacknowledged and unpaid. Themes of responsibility and justice broaden in scope in section three, 'Distributive justice in an aging society', which includes seminal papers in the debate over health care rationing and other public funding and resource problems. One emerges from this section with the bleak realisation that the challenge of marrying justice and health care, not least for the elderly, increases in magnitude as medical research and technology become more sophisticated. Nowhere is our capacity to meet this challenge in the near future asserted with total confidence.

The final section 'Philosophical reflections on aging and death', renews the discussion of senior citizens as inhabitants of individual worlds, before and beyond their place in the multitude of health care participants. Lawrence Schneiderman's portrait of age and the loving relationship draws on the author's own experiences as a doctor, as well as on classical myth, and the result is both touching and optimistic. This lighthearted and yet earnest reflection on the more affective aspects of gerontology acts as a kind of antidote to the overwhelming difficulties discussed in earlier essays. It makes a strong emotional impact without removing its attention from the necessity of re-thinking social attitudes and medical policies towards elderly individuals, and holds out some small hope for understanding how we might begin to come to terms with the complicated ethical questions arising in relation to modern medicine.

While the volume as a whole has a predominantly American texture, the issues raised in its pages have undiminished relevance for all aspects of modern health care practice and policy. Its inclusion of voices from nursing as well as philosophy and medicine is to its credit, as is its focus on the personal as well as the political side of health care issues. Aging and Ethics offers a broad spectrum of topics, eloquently considered, with many excellent essays, united by a willingness to face the unique needs of the aging and elderly patients of modern medicine.

CHERYL FOSTER

Assistant Professor of Philosophy, University of Rhode Island, USA

\section{Antenatal diagnosis of fetal abnormalities}

\author{
Edited by J O Drife and D Donnai, \\ 363 pages, London, 1991, Springer- \\ Verlag, DM 190
}

This book is the proceeding volumes derived from the 23rd Study Group of the Royal College of Obstetricians and Gynaecologists. The three-day workshop on which it is based brought together experts from many fields of clinical science and related relevant disciplines and each chapter has appended a transcript of the discus- sion arising. The work is divided into seven main sections, dealing with epidemiology; special techniques (two sections); DNA analysis and cytogenetic and biochemical disorders, an inevitable conglomerated section entitled counselling, economics and ethical issues and lastly service provision.

Although there are chapters dealing with intrauterine therapy (Rodeck and Fisk) and with diagnosis of genetic defects in eggs and embryos (Monk) it is evident throughout the technical sections that the current emphasis in antenatal diagnosis is on reducing the incidence of birth-defects by their early detection and the performance of abortion on affected pregnancies. This is made clear from the opening chapter, Trends in prevalence of congenital abnormalities (Nevin), and tables 1.5 and 1.6 show the lack of reduction in birth-prevalence of abnormalities if abortion is not readily available. It is therefore understandable that the study group should have sought a contribution from a philosopher-ethicist and further, that his chapter, Ethical aspects of prenatal diagnosis (Harris), should concentrate on a defence of aborting fetuses with known abnormalities. Harris does this with his usual succinct and eloquent ease. He predominantly concentrates on the 'aborting Beethoven' argument and declines to accept that allowing the suffering of abnormal and handicapped individuals is justified either to retain the works of those artistic geniuses who might have suffered such a handicap or, a superficially more rational but scientifically less well-founded argument, to maintain the diversity of the human genome and its evolutionary potential.

However, Harris's chapter is not the only one giving rise to ethically relevant questions. Not surprisingly, the cost of extending prenatal diag nostic services to screen women at relatively low risk, or for relatively less common conditions, has to be addressed and the difficulties in fully assessing tangible and intangible benefits of such a programme are enumerated in the chapter on Economic aspects (Henderson). Here we are weighing the cost for society of nurturing an affected infant against the cost of providing for diagnosis and abortion. Not all these costs are easily assessed financially, for example the grief caused by delivery and rearing of an abnormal child and the anxiety aroused during the diagnostic process. This latter issue is also 
addressed in the chapter on Psychological implications (Marteau), in which the available knowledge about the potential effects of either positive or negative results from various screening tests are discussed.

Containing a number of authoritative reviews of some of the key technologies, this book is not only comprehensive in its coverage of a very rapidly advancing field, it also provides a basis for consideration of further questions. The Conclusion and Recommendations do much to emphasise the extensive diagnostic capabilities of current methods such as ultrasound scanning. However, the wisdom of devoting more and more resources to the detection of rarer and rarer conditions is not directly questioned. Perhaps that is what Recommendation 19 (page 355) implies!

DAVID R BROMHAM

Senior Lecturer

Academic Unit of Obstetrics and Gynaecology,

St fames's University Hospital, Leeds LS9 7TF 